\title{
ББК 75.1
}

\section{АКВААЭРОБИКА КАК СРЕДСТВО ПОВЫШЕНИЯ МОТИВАЦИИ ОБУЧАЮЩИХСЯ ВУЗОВ К ЗАНЯТИЯМ ПЛАВАНИЕМ}

\section{Е.Г. Монахова}

Аннотация. $B$ статье раскрываются проблель мотивации студенток к занятиял плаванием в ралках учебной дисииплинь "Элективные дисииплины по обизической культуре и спорту". Проанализированы данные научной литературы, отражаюшие илеюшийся опьт обучения плаванию, которые свидетельствуют о тол, что обучение плаванию по общепринятой летодике не соответствуют интересал большинства девушек-студенток, так как в студенческол возрасте девушки уделяют значительное внилание красоте своего тела. Поэтому они делают выбор в пользу тех систел ббизических упражнений, которые способствуют гарлоничнолу развитию тела. У них наблюдается повышенный интерес к различныл направлениял оздоровительной аэробики как на суше, так и в воде, наприлер, $\kappa$ аквааэробике. Цель исследования состоит в обосновании и эксперилентальной проверке эбббективности приленения аквааэробики в учебнол процессе вуза. Вылвлены преилущества аквааэробики перед обучениел плаванию по общепринятой методике, главное из которых заключается в эбббективнол снижении психоэлоционального напряжения во вреля занятий в воде и бборлировании навыка плавания. Составлена програлла исследования, которое показало, что приленение упражнений аквааэробики способствует не только развитию плавательного навька у студенток, но и повышению мотивации обучающихся к занятиял плаваниел. Введение аквааэробики в практику процесса обучения плаванию девушек позволит повысить эбббективность процесса обучения по данной дисииплине.

Ключевые слова: аквааэробика, плавание, мотиваиия, фбизическая подготовленность, педагогический эксперилент. 


\title{
WATER AEROBICS AS A MEANS OF INCREASING MOTIVATION OF STUDENTS TO SWIMMING
}

\section{E.G. Monakhova}

\begin{abstract}
The article reveals the problems of motivating students to do swimming in the framework of the academic discipline "Elective disciplines in physical education and sports". Swimming training according to the generally accepted methodology does not correspond to the interests of most female students. At a student age, girls pay significant attention to the beauty of their body, so they choose the systems of physical exercises that contribute to the harmonious development of the body. They have an increased interest in various areas of health-improving aerobics both on land and in water, for example, water aerobics. The main advantage of water aerobics is the possibility of including students of various levels of physical fitness in the classes. In addition, physical exercises in water effectively relieve psycho emotional stress and form swimming skills. The introduction of water aerobics into the practice of the process of teaching swimming girls will improve the effectiveness of the learning process in this discipline.
\end{abstract}

Keywords: water aerobics, swimming, motivation, physical fitness, pedagogical experiment.

A ктуальность социально-экономических редрорм в России предъявляет высокие требования к физической культуре личности. Это отражено в законодательстве Российской Федерации в срере фризической культуры и спорта. Необходимость занятий фоизическими упражнениями обусловлена целями физического развития и наращивания фризической подготовки человека, способного к реализации в полной мере профессиональных видов деятельности.

Специфическая особенность процесса фризического воспитания в высших учебных заведениях состоит в его утилитарном, практическом характере, который предполагает готовность будущих специалистов к профрессиональной практике и активной деятельности. Фундаментом этого процесса является эфрфективность применения разнообразных средств фризической культуры и спорта не только для сохранения и укрепления здоровья, но и для подготовки к будущей жизни и профрессиональной деятельности.

Федеральный государственный образовательный стандарт высшего образования 3 поколения предусматривает реализацию двух дисциплин: «Физическая культура» (72 часа) и «Элективные дисциплины по физической культуре и спорту» (328 часов), которые являются обязательными для освоения.

«Элективные дисциплины по фризической культуре и спорту» в Новокузнецком институте (фолиале) Кемеровского государственного университета реализуется в виде следую- 
щих занятий обучающихся: баскетбол, волейбол, легкая атлетика, плавание. Выбор этих видов фоизической активности не случаен.

Спортивные игры оказывают благоприятное действие на весь организм. В процессе игры в волейбол, футбол, баскетбол, гандбол и др. при выполнении разнообразных движениях участвует практически вся мышечная система человека и таким образом происходит развитие и совершенствование мускулатуры, развиваются скоростные и силовые качества, ловкость, умение сохранять равновесие, координация движений и т.п. Регулярные занятия этими динамичными видами спорта хорошо повышают выносливость организма, тренируют дыхательный аппарат человека, благоприятно влияют на работу сердечно-сосудистой системы, укрепляют нервную систему. Большое значение имеет и то, что игра всегда сопровождается эмоциональным подъемом.

Легкоатлетические упражнения оказывают разностороннее воздействие на организм занимающихся: формируют и совершенствуют силу, гибкость, выносливость ловкость, быстроту, способствуют приобретению многих локомоторных умений и навыков. Занятия легкой атлетикой оказывают положительное воздействие на системы организма: тренируют и совершенствуют работу фонкциональных систем организма, опорно-двигательного аппарата, способствуют гармоничному развитию различных групп мышц.

Занятия плаванием способствуют формированию правильной осанки, что необходимо для нормального функционирования организма. За- нятия в бассейне также позитивно сказывается на дыхательной системе: увеличивается объем легких, улучшается их вентиляция, совершенствуется работа органов дыхания. Упражнения в прохладной воде способствуют укреплению иммунной системы, что является профилактикой множества болезней. Наконец, занятия плаванием положительно сказываются на нервной системе и психическом состоянии человека. Время, проведенное в воде, снимает возбуждение, успокаивает, способствует нормализации сна и повышению настроения $[1 ; 2]$.

Кроме того, умение плавать для большинства людей является жизненно важным и насущным умением, основным условием гарантии безопасности на воде. Люди, не умеющие плавать, погибают на воде в 5-6 раз чаще, чем умеющие. Согласно статистике за последние пять лет в России утонуло в среднем 14 тысяч человек в год, а треть взрослого населения Российской Федерации вообще не умеют плавать [3; 4].

Постановка проблемы. Анализ публикаций, отражающих имеющийся опыт обучения плаванию различных категорий населения, позволил сделать некоторые умозаключения. Во-первых, более половины студентов-первокурсников не только не владеют техникой спортивных способов плавания (кроль, брасс, баттердляй), но не могут даже держаться на воде.

Во-вторых, большинство умеющих плавать студентов приобрели этот навык не намерено (во время отдыха на водоеме, в гостях у друзей за городом, «за компанию» и т.д.). Только десятая часть студентов посещали спортивные секции по плаванию 
или обучались технике плавания под руководством тренера в загородных оздоровительных лагерях.

В-третьих, имеются значительные сложности в обучении плаванию молодежи. Для большинства не умеющих плавать юношей и девушек самым сложным в процессе обучения плаванию является преодоление чувство страха воды и, особенно, глубины. У молодых людей, которые могут держаться на воде, как правило, уже сформирован навык неправильного положения и перемещений в воде, что исправить намного сложнее, нежели научить заново [5-8].

Бездеятельное, а иногда и отрицательное отношение студентов к занятиям по плаванию ставит преподавателей вузов перед необходимостью искать новые способы вовлечения студентов, особенно первокурсников, в активную двигательную деятельность, предусмотренную данной дисциплиной. Разрешить выявленные противоречия возможно, применив в учебном процессе аквааэробику, так как приемы и средства данного вида двигательной активности способствуют формированию плавательного навыка, снижают уровень психоэмоционального напряжения, повышают эфрфективность занятий плаванием, укрепляют здоровье, улучшают общее самочувствие.

Организация и методика исследования. Исследование проводилось с сентября 2017 года по май 2019 года в Новокузнецком институте (филиале) Кемеровского государственного университета на базе спортивно-оздоровительного комплекса «Олимп». На первом этапе исследования (2017-2018 учебный год) производился теоретический анализ на- учной и методической литературы, формулировался объект и предмет исследования. На базе проанализированных научных теорий и концепций выявлялись противоречия, формулировалась гипотеза исследования, разрабатывалась методика занятий с применением комплексов упражнений аквааэробики.

Гипотеза заключается в том, что применение аквааэробики в учебном процессе вуза повысит интерес студенток к занятиям на воде, поспособствует формированию плавательного навыка, снизит уровень психоэмоционального напряжения и обеспечит позитивный эмоциональный настрой, что создаст хорошие условия для повышения эфрфективности занятий плаванием.

С целью решения поставленных задач и проверки выдвинутой гипотезы нами использовался комплекс методов исследования: теоретические (анализ, обобщение данных научно-методической литературы); эмпирические (анкетирование, индивидуальные беседы, педагогические наблюдения, педагогический эксперимент); статистические.

Важными для нашего исследования являются работы по основам теории и методике проведения занятий по аквааэробике [9-11]; теоретические положения о содержании, средствах и методах занятий аквааробикой [1214]; концепщия фризкультурно-оздоровительной работы с женским студенческим контингентом [15].

Индивидуальные беседы со студентами и педагогические наблюдения проводились в условиях учебного процесса на практических занятиях по плаванию в рамках учебной дисциплины «Элективные дисциплины по 
фризической культуре и спорту» для получения информации об отношении первокурсниц к данной дисциплине, a также для формулирования рабочей гипотезы исследования.

Содержание исследования. В соответствии с планом исследования было проведено первичное анкетирование студенток-первокурсниц для определения их отношения и интереса к занятиям плаванием. Анкета содержала 10 вопросов, которые позволили оценить интерес обучающихся к учебным занятиям на воде и их отношение к экспериментальной методике. Анкетирование показало, что 26 первокурсниц (32\%) вообще не умеют плавать. Из 56 умеющих плавать студенток спортивными видами плавания (кроль на груди, брасс) владеют 9 человек (16\%). Свое отношение к учебным занятиям по плаванию 65\% респондентов оценили как «неудовлетворительное» (оценка 1-2 балла по пятибалльной шкале). Большинство девушек (53\%) в качестве причины нежелания посещать занятия в бассейне указали монотонность, однообразие занятий («скучно плавать от бортика к бортику»), $19 \%$ - из-за сложности заданий, 17\% мерзнут в воде, 11\% стесняются своего тела. Как следствие отношения студентов к занятиям плаванием посещаемость учебных занятий в бассейне очень низкая - 38\%. В каче- стве альтернативы плаванию 87\% студенток в своих анкетах указали аквааэробику.

Студенткам было предложено оценить по 5-тибалльной шкале уровень своего психоэмоционального напряжения, самочувствие и настроение во время занятий плаванием (таблица 1).

Таблица 1

Самооценка студенток I курса во время занятий плаванием

\begin{tabular}{|l|c|}
\hline \multicolumn{1}{|c|}{ Показатели } & Средний балл \\
\hline Психоэмоциональное напряжение & 4,1 \\
\hline Самочувствие & 2,2 \\
\hline Настроение & 2,6 \\
\hline
\end{tabular}

Проведенное анкетирование выявило недостаточное использование возможностей существующей практики организации и проведения учебных занятий по плаванию для удовлетворения интересов девушекстуденток по данному виду фризической активности.

Экспериментальная часть. В эксперименте приняли участие студентки I курса фракультета психологии и педагогики в количестве 82 человек, имеющих медицинский допуск к занятиям плаванием. Из обучающихся, участвовавших в эксперименте, были сформированы экспериментальная и контрольная группы (таблица 2).

Таблица 2

Состав контрольной и экспериментальной групп

\begin{tabular}{|l|c|c|c|c|c|c|}
\hline \multirow{2}{*}{$\begin{array}{c}\text { Категория } \\
\text { обучающихся }\end{array}$} & \multicolumn{3}{|c|}{ Контрольная группа (41 чел.) } & \multicolumn{3}{c|}{ Экспериментальная группа (41 чел.) } \\
\cline { 2 - 7 } & $\mathbf{K Г - 1}$ & $\mathbf{K Г - 3}$ & $\mathbf{K Г - 3}$ & ЭГ-1 & ЭГ-2 & ЭГ-3 \\
\hline Умеющие плавать & 9 & 10 & 9 & 10 & 9 & 9 \\
\hline Не умеющие плавать & 4 & 4 & 5 & 4 & 5 & 4 \\
\hline Всего & 13 & 14 & 14 & 14 & 14 & 13 \\
\hline
\end{tabular}


В течение 2018-2019 учебного года был проведен педагогический эксперимент. Занятия по аквааэробике проводились два раза в неделю продолжительностью 60 минут. В обеих группах было проведено одинаковое количество учебных занятий по плаванию. В контрольной группе обучение плаванию осуществлялось по общепринятой методике обучения, а в экспериментальной - средствами аквааэробики. Занятия аквааэробикой состояли из вводной, основной и заключительной частей. Вводная часть занятия включала в себя кардио разминку, упражнения с малой амплитудой движений на основные группы мышц и упражнения на растягивание. Основная часть состояла из комплексов упражнений в неглубокой воде различной степени сложности (ходьба и бег на месте, подскоки, прыжки, махи, выпады, с погружением под воду, задержкой дыхания), танцевальной аэробики и упражнений с использованием различных предметов (мячи, доски, гантели и др.). Заключительная часть содержала упражнения на релаксацию и стретчинг.

Результаты исследования. После проведения эксперименталь- ной работы были получены следующие результаты.

1. Эфрдективность применения средств аквааэробики подтверждается степенью удовлетворенности студенток занятиями плаванием. При повторном анкетировании на вопрос «Ваше отношение к учебным занятиям по плаванию» 93\% респондентов экспериментальной группы высказали свое положительное отношение к проведенным занятиям (рис. 1).

2. В экспериментальной группе уменьшилось количество не умеющих плавать студентов: из 13 студенток 7 человек научились плавать, 4 - уверенно держаться на воде.

3. Наблюдается положительная динамика самооценки студенток экспериментальной группы во время занятий плаванием (рис. 2).

Выводы. Результаты анкетирования студенток и индивидуальных бесед с ними, педагогических наблюдений дают основание сделать следующий вывод: небольшой интерес девушек к занятиям по плаванию обусловлен сложностью преодоления страха воды, некомфортностью нахождения под водой, сложностью заданий при обучении плаванию по общепринятой методике.

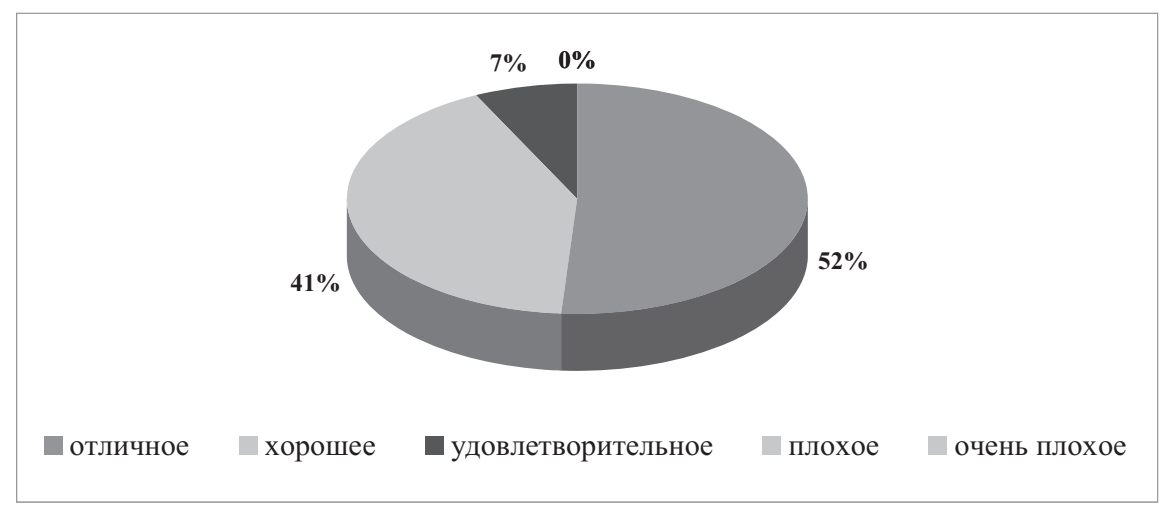

Puc. 1. Отношение студенток экспериментальной группы к занятиям плаванием 


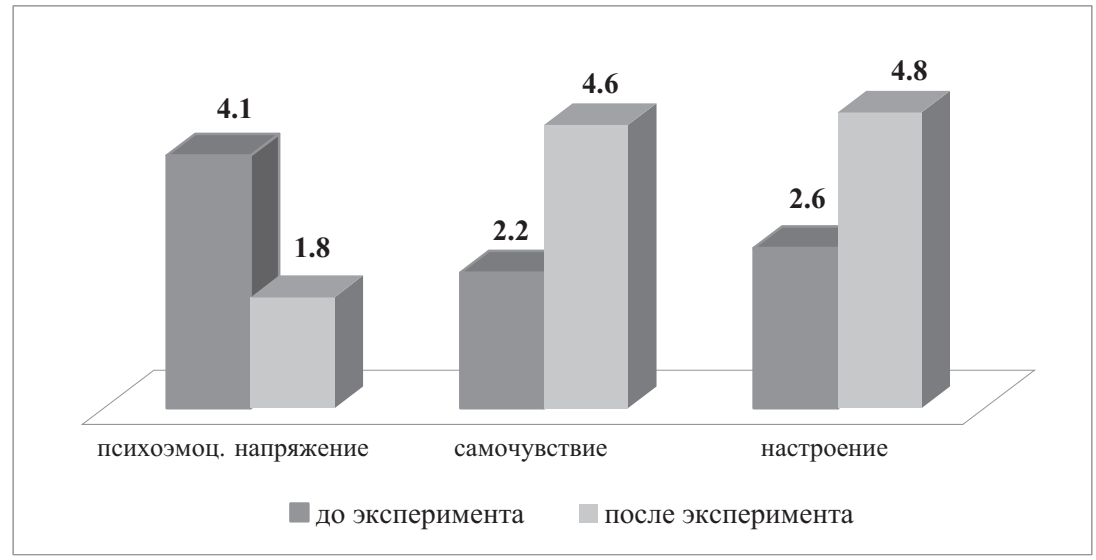

Puc. 2. Самооценка студенток экспериментальной группы во время занятий плаванием.

Педагогический эксперимент показал, что применение упражнений аквааэробики не только увеличивают выбор средств и обновляют методические подходы при занятиях на воде, но и снижают психоэмоцио- нальное напряжение, увеличивают настроение и самочувствие занимающихся, способствует развитию плавательного навыка, что приводит к повышению мотивации обучающихся к занятиям плаванием.

\section{СПИСОК ИСТОЧНИКОВ И ЛИТЕРАТУРЫ}

1. Мельникова, O.A. Организация и особенности обучения плаванию студентов с учетом индивидуального фенотипа: монография. Омск: Изд-во ОмГТУ, 2013, 155 с.

2. McCleod, I. Swimming anatomy. USA: «Human Kinetics», 2010. 200 p.

3. Турчанинов, С.Ю. Плавание - жизненно важный навык: автореф. дис. ... канд. пед. наук: 13.00.04. Ярославль, ЯГПУ. 2005. 24 с.

4. Демографический ежегодник России. Стат. сб. Росстат. М., 2017. 263 с.

5. Казакова, Н.А. Повышение физической подготовленности девушек в возрасте 17-19 лет на основе средств аквааэробики: дис. ... кан. пед. наук: 13.00.04. М.: Рос. гос. ун-т физ. культуры, спорта и туризма. 2009. 209 с.

6. Нижник, Г.Н. Обучение плаванию девушек 18-20 лет с использованием аквааэробики: автореферат дис. ... канд. пед. наук: 13.00.04. М.: Рос. гос. ун-т физ. культуры, спорта, молодежи и туризма. 2012. 24 с.

7. Полухина, Т.Г. Классификация и типология упражнений в аквааэробике как основа для разработки технологии обучения: дис. ... канд. пед. наук: 13.00.04. М.: Рос. гос. ун-т физ. культуры, спорта и туризма. 2003. 160 с.

8. Kjendlie, P.L., Stallman, R.K., Cabri, J. The evolution of swimming science research: content analysis of the "biomechanics and medicine in swimming" proceedings books from 1971 to 2006 // Biomechanics and medicine in swimming XI. 2010. P. 312-314.

9. Булгакова, Н.Ж. Адаптивная и лечебная физическая культура. Плавание: учеб. пособие для академического бакалавриата. 3-е изд., перераб. и доп. М.: Издательство Юрайт, 2019. $401 \mathrm{c}$. 
10. Васильева, И.А. Содержание и методика занятий водной аэробикой с женщинами зрелого возраста: автореферат дис. ... канд. пед. наук: 13.00.04. М.: Рос. акад. физ. культуры, 1997, 23 с.

11. Колганова, Е.Ю. Влияние занятий аквааэробикой на состояние организма женщин разного возраста: автореферата дис. ... кан. пед. наук: 13.00.04. Малаховка, Московская гос. акад. физ. культуры. 2007. 23 с.

12. Курятникова, Л.Ф. Технология обучения плаванию студенток педагогического вуза на основе использования игрового метода: дис. ... канд. пед. наук: 13.00.04. М., 2005. 197 с.

13. Меньшуткина, Т.Г. Теория и методика оздоровительного плавания женщин разного возраста: дис. ... д-ра пед. наук: 13.00.04. С.-Петерб. гос. акад. физ. культуры им. П.Ф. Лесгафта. СПб., 2000. 332 с.

14. Лоуренс, Дэбби. Аквааэробика: Упражнения в воде: практ. руководство. М.: Гранд: ФАИРПРЕСС, 2000. $254 \mathrm{c}$.

15. Лубышева, Л.И. Социология физической культуры и спорта: учеб. пособие. М.: Академия, 2001. $240 \mathrm{c}$.

\section{REFERENCES}

1. Bulgakova N.Zh., Adaptivnaja i lechebnaja fizicheskaja kultura. Plavanie: ucheb. posobie dlja akademicheskogo bakalavriata. Moscow, Izdatelstvo Jurajt, 2019, 401 p. (in Russian)

2. Demograficheskij ezhegodnik Rossii, Stat. sb. Rosstat. Moscow, 2017, 263 p. (in Russian)

3. Kazakova N.A. Povyshenie fizicheskoj podgotovlennosti devushek v vozraste 17-19 let na osnove sredstv akvaajerobiki: PhD dissertation (Pedagogy). Moscow, Ros. gos. un-t fiz. kultury, sporta i turizma, 2009, 209 p. (in Russian)

4. Kjendlie P.L., Stallman R.K., Cabri J. "The evolution of swimming science research: content analysis of the "biomechanics and medicine in swimming" proceedings books from 1971 to 2006", in: Biomechanics and medicine in swimming XI. 2010, pp. 312-314.

5. Kolganova E.Ju. Vlijanie zanjatij akvaajerobikoj na sostojanie organizma zhenshhin raznogo vozrasta: Extended Abstract of PhD dissertation (Pedagogy). Malahovka, Moskovskaja gos. akad. fiz. kultury, 2007, 23 p. (in Russian)

6. Kurjatnikova L.F. Tehnologija obuchenija plavaniju studentok pedagogicheskogo vuza na osnove ispolzovanija igrovogo metoda: PhD dissertation (Pedagogy). Moscow, Moskovskij gos. obl. un-t., 2005, 197 p. (in Russian)

7. Lourens Djebbi. Akvaajerobika: Uprazhnenija v vode: prakt. Rukovodstvo. Moscow, Grand, FAIR-PRESS, 2000, 254 p. (in Russian)

8. Lubysheva L.I. Sociologija fizicheskoj kultury i sporta: ucheb. posobie. Moscow, Akademija, 2001, 240 p. (in Russian)

9. McCleod I. Swimming anatomy, USA: Human Kinetics, 2010. 200 p.

10. Melnikova O.A. Organizacija i osobennosti obuchenija plavaniju studentov s uchetom individualnogo fenotipa: monografija. Omsk, OmGTU, 2013, 155 p. (in Russian)

11. Menshutkina T.G. Teorija i metodika ozdorovitelnogo plavanija zhenshhin raznogo vozrasta: ScD dissertation (Pedagogy). Sankt-Petersburg, S.-Peterb. gos. akad. fiz. kultury im. P.F. Lesgafta, 2000, 332 p. (in Russian)

12. Nizhnik G.N. Obuchenie plavaniju devushek 18-20 let s ispolzovaniem akvaajerobiki: Extended Abstract of PhD dissertation (Pedagogy). Moscow, Ros. gos. un-t fiz. kultury, sporta, molodezhi i turizma. 2012. 24 p. (in Russian) 
13. Poluhina T.G. Klassifikacija i tipologija uprazhnenij v akvaajerobike kak osnova dlja razrabotki tehnologii obuchenija: PhD dissertation (Pedagogy). Moscow, Ros. gos. un-t fiz. kultury, sporta i turizma, 2003, 160 c. (in Russian)

14. Turchaninov S.Ju. Plavanie - zhiznenno vazhnyj navyk: Extended Abstract of PhD dissertation (Pedagogy). Jaroslavl, JaGPU, 2005, 24 p. (in Russian)

15. Vasileva I.A. Soderzhanie i metodika zanjatij vodnoj ajerobikojs zhenshhinami zrelogo vozrasta: Extended Abstract of PhD dissertation (Pedagogy). Moscow, Ros. akad. fiz. kultury, 1997, 23 p. (in Russian)

Монахова Елена Геннадьевна, кандидат педагогических наук, доцент, кафедра физической культуры, Новокузнецкий институт (филиал), Кемеровский государственный университет, monakhova.lena2011@yandex.ru

Monakhova E.G., PhD (in Pedagogy), Associate Professor, Department of Physical Culture, Novokuznetsk Institute (branch), Kemerovo State University, monakhova.lena2011@yandex.ru 


\title{
ББК 74.268.53
}

\section{В КЛАССЕ ЕЛЕНЫ ФАБИАНОВНЫ ГНЕСИНОЙ}

\section{Е.И. Захаренкова}

Аннотация. Статья посвящена выљающелуся российсколу педагогупианисту, создателю и руководителю колплекса музыкальных учебных заведений Елене Фабиановне Гнесиной. В статье анализируется педагогическое наследие Е.Ф. Гнесиной, ставшее ориентирол не только для специальных музыкальных, но и музыкально-педагогических учреждений России. Автор статьи также подробно расслатривает методику начального обучения пианистов, разработанную Е.Ф. Гнесиной и зафбккированную в ряде ее фбортепианных упражнений. Анализируются также приниипь построения учебного репертуара обучающихся, разработанные Е.Ф. Гнесиной.

Ключевые слова: Елена Фабиановна Гнесина, бортепианная педагогика, колплекс учебных музыкальных заведений илени Гнесиных, методика работы с начинающили пианистали.

\section{IN THE CLASS OF ELENA FABIANOVNA GNESINA}

\section{E.I. Zakharenkova}

\begin{abstract}
The article is dedicated to Elena Fabianovna Gnesina, an outstanding Russian teacher-pianist, creator and head of a complex of musical educational institutions. The article analyzes E.F. Gnesina's pedagogical heritage which has become a reference point not only for special music, but also for music and pedagogical institutions in Russia. The author of the article also considers in detail the method of pianists' initial training, developed by E.F. Gnesina and recorded in a number of her piano exercises. The article also analyzes the principles of building students' educational repertoire, developed by E.F. Gnesina.

Keywords: Elena Fabianouna Gnesina, piano pedagogy, complex of educational musical institutions named after the Gnesin, methods of working with novice pianists.
\end{abstract}

